\title{
THE IMPACT OF COVID-19 PANDEMIC AND LOCKDOWN MEASURES ON EATING DISORDER RISK AND EMOTIONAL DISTRESS AMONG ADOLESCENTS AND YOUNG PEOPLE IN SPAIN
}

\author{
Helena Vall-Roqué1, Ana Andrés² and Carmina Saldaña \\ ${ }^{1}$ University of Barcelona; ${ }^{2}$ Ramon Llull University (Spain)
}

\begin{abstract}
This cross-sectional study aimed to determine the impact of COVID-19 lockdown on emotional distress and disordered eating in a community sample of Spanish youngsters. A total of 2847 participants (95\% women; aged 14-35) completed depression, anxiety, stress, self-esteem, and disordered eating measures. Given the small proportion of men and as significant differences were found between genders in several variables, most results were only reported for women. Severe levels of depression, anxiety and stress were found in 30.8\%, $25.4 \%$ and $20.5 \%$ of the sample, respectively. Sleep quality, eating habits, appearance concerns, preoccupation about one's future, health concerns and other life domains were also affected by lockdown. Younger age, being single, being unemployed, not having contracted COVID-19 or not being sure about it, having a loved one infected or deceased due to coronavirus, and not having a place to relax at home were significantly associated with psychological distress and disordered eating. A structural equation model confirmed the direct influence of lockdown-related variables into psychopathology symptoms. The findings of this study suggest that COVID-19 and its associated lockdown might have a significant effect on psychological wellbeing and eating disturbances.

KEY WORDS: COVID-19, disordered eating, depression, anxiety, stress, emotional distress.

\section{Resumen}

El objetivo de este estudio fue determinar el impacto psicológico del confinamiento por COVID-19 en una muestra comunitaria española. 2847 participantes de entre 14 y 35 años (95\% mujeres) completaron medidas de depresión, ansiedad, estrés, autoestima y alteraciones alimentarias. Considerando la pequeña proporción de hombres y al hallar diferencias significativas entre sexos, la mayoría de resultados fueron informados solo para las mujeres. Un 30,8\%, $25,4 \%$ y $20,5 \%$ de la muestra presentó niveles graves o muy graves de depresión, ansiedad y estrés respectivamente. La calidad del sueño, los hábitos alimentarios, las preocupaciones por la apariencia física, por el futuro y por la salud habían
\end{abstract}

Correspondence: Helena Vall-Roqué, Dpt. of Clinical Psychology and Psychobiology, Faculty of Psychology, University of Barcelona, Passeig Vall d'Hebron, 17108035 Barcelona (Spain). E-mail: helena.vall@ub.edu 
empeorado a raíz del confinamiento. Una menor edad, no tener pareja, el desempleo, no haber contraído COVID-19 o no estar seguro de ello, el fallecimiento de un ser querido por COVID-19, y no tener un lugar donde relajarse fueron factores asociados al malestar psicológico y las alteraciones alimentarias. El análisis de ecuaciones estructurales confirmó la influencia directa de las variables relacionadas con el confinamiento en la psicopatología. Esto sugiere que la pandemia puede haber tenido un impacto significativo en la salud mental y en la conducta alimentaria.

PALABRAS clave: COVID-19, alteraciones alimentarias, depresión, ansiedad, estrés, malestar emocional.

\section{Introduction}

Coronavirus disease 2019 (COVID-19) is an infectious disease caused by acute respiratory syndrome coronavirus-2 (SARS-CoV-2) that spreads rapidly, posing a significant threat to global health. Even though the disease started as an epidemic mainly limited to China, it was declared a pandemic the $11^{\text {th }}$ March 2020 by the World Health Organization (WHO).

The current study was conducted in Spain, which was the third country in the world with more deaths recorded per 100,000 inhabitants when the data for this research was collected, in mid-May (John Hopkins Coronavirus Resource Center, 2020).

Consequently, a great amount of the Spanish population has been forced to remain at home for at least 6 weeks, as the Spanish cabinet declared a state of emergency on 14 March, placing the entire country in lockdown. On 28 April, the Spanish government announced a four-phase lockdown exit strategy for the country which started the $2^{\text {nd }}$ of May. This plan was divided into four phases, which were gradually implemented according to the epidemiological situation of each province. The de-escalation plan started 10 days before the data for this research was collected.

According to the review conducted by Brooks et al. (2020), quarantines are associated with negative psychological effects including post-traumatic stress symptoms, confusion, and anger. Several research articles that have been published within the last three months have stated that the COVID-19 outbreak and its associated quarantine might be linked to anxiety, depression, stress, post-traumatic stress disorder and disturbed sleep (Cao et al., 2020; Liang et al., 2020; Rajkumar, 2020). Furthermore, it has been suggested that the most vulnerable collectives might be women and young individuals (Liu et al., 2020; Ozamiz-Etxebarria, DosilSantamaria, Picaza-Gorrochategui, \& Idoiaga-Mondragon, 2020; Sun et al., 2020; Wang et al., 2020).

The relationship among variables related to the lockdown and their effect on psychological distress and psychopathology symptoms is complex. A few studies have applied structural equation modeling (SEM) to analyse the effect of variables related to the lockdown due to COVID-19 on diverse settings. Some of these studies are focused on predicting the compliance of population with prevention guidelines, or the effect of the lockdown on tourism, or customer behavioural intentions in 
stores (Plohl \& Musil, 2020; Rukini \& Maziriri, 2020; Zhu \& Deng, 2020), while others have focused on the analysis of the lockdown in psychological variables. Specifically, these studies have been carried out in China, aiming to analyze the mediation effect of alexithymia on mental health problems (Tang, Hu, Yang, \& Xu, 2020), or the impact of social capital into psychological distress and quality of sleep during the lockdown (Xiao, Zhang, Kong, Li, \& Yang, 2020). Finally, other studies have focused on the role of social support and resilience on the prevention of psychological distress of Chinese health care staff (Hou et al., 2020; Xiao et al., 2020).

However, there is a lack of studies considering the multivariate effect of the psychological impact of the lockdown on psychological distress and eating disorder risk. Moreover, only a few studies have been conducted in Spain, and the effects of COVID-19 outbreak and its associated lockdown on emotional distress and disordered eating are still largely unknown. For instance, Ozamiz-Etxebarria et al. (2020) found low levels of depression, anxiety and stress in a Northern Spanish sample when the COVID-19 outbreak had recently emerged in Spain. On the contrary, Odriozola-González, Planchuelo-Gómez, Irurtia, \& de Luis-García (2020) reported that $20-35 \%$ of their sample exhibited high levels of depression, anxiety, and stress.

This study aimed to determine the impact of COVID-19 lockdown on depression, anxiety, stress, self-esteem, and disordered eating in a community sample of Spanish adolescents and young people.

\section{Method}

\section{Participants}

A total of 3378 participants from a community sample participated in the present study. Participants that did not live in Spain, those presenting missing data in the sociodemographic questions or in the COVID-related items, women who reported to be pregnant, and those who were older than 35 years old or younger than 14 years old $(n=531)$ were excluded from the analyses, yielding the final sample of 2847 participants. 2709 participants were women (95.15\%), 128 were men $(4.50 \%)$, and 10 identified themselves as nonbinary $(0.35 \%)$.

\section{Instruments}

a) Ad hoc demographic questionnaire. Participants self-reported their age, gender, place of residence (city/town in Spain, rural area in Spain, or outside Spain), employment situation, relationship status, height, and weight. Height and weight measures were used to calculate body mass index (BMI).

b) COVID-19 and lockdown-related information ad hoc questionnaire. Participants were asked whether they had contracted COVID-19, whether they had any relative or close person who had suffered the virus and if any loved one had deceased due to COVID-19. Those who had suffered the loss of a close person due to COVID-19 also indicated whether they had had the chance to say goodbye. Participants that were enrolled in an academic course reported 
whether they had experienced any of a list of changes (problems with online lectures, increase in assignments, decrease in assignments, increase in course disorganization). Moreover, a 5-point Likert scale ranging from "has changed a lot to worse" to "has changed a lot to better" was used to assess the degree in which the following aspects of participants' life had changed since the lockdown began: eating habits, physical activity, appearance concerns, sleep quality, self-caring time, health concerns, own's future concerns, feelings of anxiety, sadness, loneliness and autonomy, consumption of alcohol, tobacco and other drugs, and family, friends, couple and sexual relationships. Higher scores indicated that participants thought that these areas had changed to better since the lockdown began. Finally, participants were asked to indicate whether they felt they had a place for themselves in their homes where they could relax.

c) Depression, Anxiety and Stress Scales-21 (DASS-21; Lovibond \& Lovibond, 1995), adapted to Spanish by Bados, Solanas, and Andrés (2005). The DASS-21 is a self-report questionnaire that measures symptoms of depression, anxiety, and stress in both clinical and non-clinical samples. Items are presented in a 4point Likert scale ranging from "Did not apply to me at all" to "Applied to me very much, or most of the time". It has three 7-item-subscales: depression, anxiety, and stress. The questionnaire has been reported to have acceptable internal reliability in Spanish samples, with Cronbach's alphas of .84, .70 and .82 for the depression, anxiety, and stress subscales, respectively (Bados et al., 2005). Cronbach's alphas in the current study were $.90, .83$, and .82 for the depression, anxiety, and stress subscales, respectively. Cronbach's alpha for the whole scale was .93.

d) Eating Attitudes Test-26 (EAT-26; Garner, Olmsted, Bohr, \& Garfinkel, 1982), adapted to Spanish by Castro, Toro, Salamero, and Guimerá (1991). The EAT26 is a 26-item self-report questionnaire that measures disordered eating behavior and attitudes. Items are presented in a 6-point Likert scale ranging from "Never" to "Always", and higher scores indicate higher levels of eating disturbances. It has three subscales: dieting, bulimia and food preoccupation, and oral control. The questionnaire has been shown to have adequate psychometric properties, and the alpha reliability coefficient in a Spanish sample was .93 (Castro et al., 1991). Cronbach's alpha in the current study was .90.

e) Rosenberg Self-Esteem Scale (RSES; Rosenberg, 1965), adapted to Spanish by Martín-Albo, Núñez, Navarro, and Grijalvo (2007). The RSES is a widely used 10item questionnaire that assesses global self-esteem and general feelings of selfworth with a 4-point Likert scale, ranging from "Strongly disagree" to "Strongly agree". Higher scores indicate higher self-esteem. The scale has been reported to have a one-factor structure and satisfactory levels of internal consistency (Cronbach's alpha of .85) in Spanish samples (Martín-Albo et al., 2007). Cronbach's alpha in this study was .91. 


\section{Procedure}

The study was approved by the University of Barcelona's Bioethics Commission. All measures were administered online through a secure internet-based website. Participants gave their informed consent before completing questionnaire measures, and they did not receive compensation for their participation. In the case of underaged participants, parental consent was not requested as the Spanish law states that it is only required for individuals under 14 years old for this type of studies (Organic Law 3/2018 for Data Protection and guarantee of Digital Rights, articles 6 and 7).

A cross-sectional web-based survey design was adopted. Participants were recruited through social networking sites from 12 May until 17 May. When the data was collected, Spanish population were allowed to engage in individual sport activities, including going for a walk, for a limited time per day. In 26 provinces (comprising $51 \%$ of the Spanish population), from 11 May it was also permitted to visit friends and family living in the same province, still with social distancing measures.

\section{Data analysis}

All data were analyzed using SPSS v. 20 and AMOS v. 20. Participants were divided into two age categories: generation $Z$, which comprised individuals that were aged from 14 to 24, and generation $Y$, which included participants that were between 25 and 35 years old. Generational cohorts were established based on Francis \& Hoefel (2018) and Duffy et al. (2018).

Cut off scores for the DASS-21, the RSES and the EAT-26 were taken from Gale (2015), Isomaa, Väänänen, Fröjd, Kaltiala-Heino, \& Marttunen (2013), and Garner et al. (1982), respectively.

Descriptive statistics (frequency, percentages, mean, and standard deviation) were used for assessing the sociodemographic characteristics of the sample, the COVID-19 and lockdown-related variables and the mental health status of participants. Chi-square tests of independence were performed to examine the relation between gender and categorical variables, and $t$ Student tests were conducted to explore the relationship between gender and the scores in all psychological variables.

Mean comparisons were conducted through Student's t tests and one-way ANOVAs in order to assess whether the sociodemographic and COVID-19 variables were significantly associated with each psychological variable. If Levene's test of homogeneity of variance was violated, the Brown-Forsyth statistic was reported. Statistically significant effects from the one-way ANOVAs were followed up by Tukey post hoc tests when data met the homogeneity of variances assumption, and by Games-Howell post hoc tests when homogeneity of variances' assumption was violated.

Structural equation modelling was conducted. Data did not fit multivariate normality according to Bentler (2005) cut-off value for Mardia's normalized estimate. Therefore, the unweighted least squares (ULS) estimation method was applied. Several goodness-of-fit indices were calculated: chi-square test, goodness- 
of-fit index (GFI), comparative fit index (CFl; Bentler, 1990), normed fit index (NFI; Bentler \& Bonet, 1980), and the standardized root mean square residual (SRMR; Jöreskog \& Sörbom, 1986). The cut-off values to determine a good fit were equal or higher than 0.90 for GFI, CFI and NFI (Jackson, Gillaspy, \& Purc-Stephenson, 2009), and equal or lower than 0.08 for SRMR (Hu \& Bentler, 1999).

Descriptive analyses considering COVID-19 variables and psychological status of participants were conducted with the whole sample. However, taking into consideration the small proportion of men in the sample, the significant differences found between men and women in a number of sociodemographic and psychological variables, and the differential psychological impact of COVID-19 in men and women reported in the literature (e.g., Liu et al., 2020; Sun et al., 2020; Wang et al., 2020), only women were included in the results regarding the perceived changes due to COVID-19, the ANOVAs and the structural equation model.

\section{Results}

\section{Descriptive statistics}

Participants ranged in age from 14 to 35 , with a mean age of 24.08 years $(S D=$ $5.04)$ in women and 22.79 years $(S D=4.62)$ in men. 1678 women $(61.9 \%$ of the women subsample) and 99 men ( $77.3 \%$ of the men subsample) were aged between 14 and 24, and 1031 women and 29 men were aged between 25 and 35. Mean sample BMI was $23.80 \mathrm{~kg} / \mathrm{m}^{2}(S D=5.07)$ in women, and $24.26 \mathrm{~kg} / \mathrm{m}^{2}(S D=4.89)$ in men. The frequencies and percentages of the other sociodemographic and COVID19-related variables are reported in Table 1.

Chi-square tests of independence were performed to examine the relation between gender and sociodemographic and COVID-19-related variables. Statistically significant differences were found between genders in the following variables: employment status $\left(\chi^{2}=13.43, p<.05\right)$, current and pre-lockdown relationship status $\left(\chi^{2}=15.33, p<.001, \chi^{2}=16.77, p<.001\right.$, respectively), and feeling of having a place to relax at home $\left(\chi^{2}=8.81, p<.01\right)$.

\section{Psychological status of participants}

Means and standard deviations of the scores in each psychological questionnaire are shown in Table 2, together with mean comparisons between the scores of men and women. It should be noted that sample sizes differ among questionnaires as not all participants completed all measures. DASS-21 was fulfilled by 2512 women and 112 men, RSES by 2360 women and 104 men, and EAT-26 by 2402 women and 108 men. Significant differences between genders were found in dieting and bulimia and food preoccupation.

Table 3 shows the frequencies and percentages of participants' psychological status' levels. Significant differences between men and women were found in eating disturbances. 
Table 1

Participants' sociodemographic, COVID-19 and lockdown-related descriptive statistics divided by gender and age group

\begin{tabular}{|c|c|c|c|c|}
\hline \multirow[b]{2}{*}{ Variables } & \multicolumn{2}{|c|}{ Women } & \multicolumn{2}{|c|}{ Men } \\
\hline & $\begin{array}{l}\text { Aged } \\
14-24 \\
n(\%)\end{array}$ & $\begin{array}{l}\text { Aged } \\
25-35 \\
n(\%)\end{array}$ & $\begin{array}{l}\text { Aged } \\
14-24 \\
n(\%)\end{array}$ & $\begin{array}{l}\text { Aged } \\
25-35 \\
n(\%)\end{array}$ \\
\hline \multicolumn{5}{|l|}{ Place of residence } \\
\hline City or town in Spain & $1028(61.3)$ & $621(60.2)$ & $56(56.5)$ & $15(51.7)$ \\
\hline Rural area in Spain & $650(38.7)$ & $410(39.8)$ & $43(43.4)$ & $14(48.3)$ \\
\hline \multicolumn{5}{|l|}{ Employment status } \\
\hline Not working (e.g., student) & $1220(72.7)$ & $167(16.2)$ & $76(76.8)$ & $4(13.8)$ \\
\hline Employee/Self-employed & $244(14.3)$ & $541(52.4)$ & $12(12.1)$ & $16(55.2)$ \\
\hline Temporary leave & $13(0.8)$ & $44(4.3)$ & $1(1)$ & $2(6.9)$ \\
\hline Unemployed & $120(7.2)$ & $158(15.3)$ & $9(9.1)$ & $6(20.7)$ \\
\hline Other & $85(5.1)$ & $121(11.7)$ & $1(1)$ & $1(3.4)$ \\
\hline \multicolumn{5}{|l|}{ Current relationship status } \\
\hline Single & $892(53.2)$ & $230(22.3)$ & $65(65.7)$ & $10(34.5)$ \\
\hline In a relationship/Married & $772(46)$ & $793(76.9)$ & $34(34.3)$ & $19(65.5)$ \\
\hline Other & $14(0.8)$ & $8(0.8)$ & - & - \\
\hline \multicolumn{5}{|l|}{$\begin{array}{l}\text { Relationship status before } \\
\text { lockdown }\end{array}$} \\
\hline Single & $839(50)$ & $215(20.9)$ & $63(63.6)$ & $10(34.5)$ \\
\hline In a relationship/Married & $820(48.9)$ & $806(78.2)$ & $35(35.4)$ & $19(65.5)$ \\
\hline Other & $19(1.1)$ & $10(1)$ & $1(1)$ & - \\
\hline \multicolumn{5}{|l|}{ Infected with COVID-19 } \\
\hline Yes & $39(2.3)$ & $35(3.4)$ & $2(2)$ & - \\
\hline No & $1252(74.6)$ & $708(68.7)$ & $77(77.8)$ & $22(75.9)$ \\
\hline Not sure & $387(23.1)$ & $288(27.9)$ & $20(20.2)$ & $7(24.1)$ \\
\hline \multicolumn{5}{|l|}{$\begin{array}{l}\text { Loved one infected with COVID- } \\
19\end{array}$} \\
\hline Yes & $622(37.1)$ & $401(38.9)$ & $36(36.4)$ & $8(27.6)$ \\
\hline No & $852(50.8)$ & $505(49)$ & $51(51.5)$ & $15(51.7)$ \\
\hline Not sure & $204(12.2)$ & $125(12.1)$ & $12(12.1)$ & $6(20.7)$ \\
\hline \multicolumn{5}{|l|}{$\begin{array}{l}\text { Loved one deceased due to } \\
\text { COVID-19 }\end{array}$} \\
\hline Yes & $183(10.9)$ & $117(11.3)$ & $8(8.1)$ & $2(6.9)$ \\
\hline No & $1495(89.1)$ & $914(88.7)$ & $91(91.9)$ & $27(93.1)$ \\
\hline \multicolumn{5}{|c|}{$\begin{array}{l}\text { If a loved one deceased: could say } \\
\text { goodbye }\end{array}$} \\
\hline Yes & $1(0.5)$ & $7(6)$ & - & - \\
\hline No & $182(99.5)$ & $110(94)$ & $8(100)$ & $2(100)$ \\
\hline \multicolumn{5}{|l|}{ Own space to relax at home } \\
\hline Yes & $1263(75.3)$ & $627(60.8)$ & $84(84.8)$ & $21(72.4)$ \\
\hline No & $415(24.7)$ & $404(39.2)$ & $15(15.2)$ & $8(27.6)$ \\
\hline
\end{tabular}

Note: Percentages are presented per column. 
Table 2

Mean scores of psychological measures and comparisons between men and women's scores

\begin{tabular}{|l|c|c|c|c|c|}
\hline \multicolumn{1}{|c|}{ Variables } & Range & $\begin{array}{c}\text { Women } \\
M(S D)\end{array}$ & $\begin{array}{c}\text { Men } \\
M(S D)\end{array}$ & $t$ & $\begin{array}{c}\text { Hedges' g } \\
{[95 \% \mathrm{CI}]}\end{array}$ \\
\hline Depression & $0-42$ & $16.15(10.84)$ & $17.61(11.40)$ & 1.389 & \\
\hline Anxiety & $0-42$ & $10.42(9.25)$ & $9.05(7.67)$ & -1.825 & \\
\hline Stress & $0-42$ & $17.05(9.23)$ & $16.71(8.85)$ & -0.376 & \\
\hline Self-esteem & $10-40$ & $27.52(6.48)$ & $27.67(6.56)$ & 0.242 & \\
\hline Dieting & $0-39$ & $5.78(6.64)$ & $3.53(4.46)$ & $-4.996^{* * *}$ & $.34[.15 ; .54]$ \\
\hline $\begin{array}{l}\text { Bulimia and food } \\
\text { preoccupation }\end{array}$ & $0-18$ & $1.57(2.55)$ & $1.10(1.52)$ & $-3.036^{* *}$ & $.19[-.01 ; .38]$ \\
\hline Oral control & $0-21$ & $2.01(2.73)$ & $1.54(2.95)$ & -1.760 & \\
\hline
\end{tabular}

Notes: Sample sizes differ among questionnaires as not all participants completed all measures. DASS-21 was fulfilled by 2512 women and 112 men, RSES by 2360 women and 104 men, and EAT-26 by 2402 women and 108 men. ${ }^{*} p<.05 ;{ }^{* *} p<.01 ;{ }^{* *} p<.001$.

Table 3

Frequencies and percentages of participants' psychological status categories and differences between genders

\begin{tabular}{|c|c|c|c|c|}
\hline Variables/levels & $\begin{array}{c}\text { Women } \\
n(\%)\end{array}$ & $\begin{array}{c}\text { Men } \\
n(\%)\end{array}$ & $\begin{array}{l}\text { Total } \\
n(\%)\end{array}$ & $\chi^{2}$ \\
\hline Depression & & & & $\chi^{2}(4,2624)=8.19, p=.85$ \\
\hline No evidence & $805(32)$ & $29(25.9)$ & $834(31.8)$ & \\
\hline Mild & $385(15.3)$ & $21(18.8)$ & $406(15.5)$ & \\
\hline Moderate & $554(22.1)$ & $24(21.4)$ & $578(22)$ & \\
\hline Severe & $303(12.1)$ & $8(7.1)$ & $311(11.9)$ & \\
\hline Extremely severe & $465(18.5)$ & $30(26.8)$ & $495(18.9)$ & \\
\hline Anxiety & & & & $\chi^{2}(4,2624)=9.01, p=.61$ \\
\hline No evidence & $1137(45.3)$ & $51(45.4)$ & $1188(45.3)$ & \\
\hline Mild & $222(8.8)$ & $10(8.9)$ & $232(8.8)$ & \\
\hline Moderate & $507(20.2)$ & $32(28.6)$ & $539(20.5)$ & \\
\hline Severe & $215(8.6)$ & $10(8.9)$ & $225(8.6)$ & \\
\hline Extremely severe & $431(17.2)$ & $9(8)$ & $440(16.8)$ & \\
\hline Stress & & & & $\chi^{2}(4,2624)=2.48, p=.648$ \\
\hline No evidence & $1162(46.3)$ & $50(44.6)$ & $1212(46.2)$ & \\
\hline Mild & $396(15.8)$ & $21(18.8)$ & $417(15.9)$ & \\
\hline Moderate & $434(17.3)$ & $23(20.5)$ & $457(17.4)$ & \\
\hline Severe & $360(14.3)$ & $12(10.7)$ & $372(14.2)$ & \\
\hline Extremely severe & $160(6.4)$ & $6(5.4)$ & $166(6.3)$ & \\
\hline Self-esteem & & & & $\chi^{2}(1,2464)=0.06, p=.813$ \\
\hline Adequate or high & $1592(67.5)$ & $69(66.3)$ & $1661(67.4)$ & \\
\hline Low & $768(32.5)$ & $35(33.7)$ & $803(32.6)$ & \\
\hline Eating disorders risk & & & & $\chi^{2}(1,2510)=8.81, p=.003 * *$ \\
\hline Low risk & $2076(86.4)$ & $104(96.3)$ & $2180(86.9)$ & \\
\hline High risk & $326(13.6)$ & $4(3.7)$ & $330(13.1)$ & \\
\hline
\end{tabular}

Notes: Percentages are presented per column. Sample sizes differ among questionnaires as not all participants completed all measures. ${ }^{*} p<.05 ;{ }^{* *} p<.01 ;{ }^{* *} p<.001$. 
Perceived changes due to COVID-19 and its associated lockdown in women

At an academic level, $38.1 \%$ of women reported that they were currently not studying. From the other respondents, $48.69 \%$ had experienced problems with the online lectures (e.g., connectivity issues), $61.58 \%$ considered that there had been an increase in assignments since the lockdown began (e.g., homework), 9.96\% had experienced a decrease in assignments, $73.87 \%$ reported an increase in the courses disorganization, and $10.38 \%$ indicated that they had not experienced significant changes. Table 4 shows the frequencies and percentages of the participants' perceived changes in several life domains.

Relationship between sociodemographic and COVID-19/lockdown-related variables and psychological status in women

One-way ANOVA and $t$-test results are shown in Table 5. The analyses revealed that the younger age group had significantly higher levels of depression, anxiety, stress and oral control, and significantly lower levels of self-esteem, than the older group. Place of residence did not have a significant association with any psychological variable. Employment situation was significantly related to depression, anxiety, stress, self-esteem, and oral control. Post-hoc analyses indicated that participants who were not working (e.g., students) scored significantly higher in depression, anxiety, stress, and oral control, and significantly lower in self-esteem, compared to those who were employees or self-employed. Similarly, those who reported to be unemployed showed significantly higher levels of depression, anxiety, and stress, and a lower self-esteem, than participants that were employed or selfemployed. Significant differences were found in depression, self-esteem, and oral control across relationship statuses. Post-hoc analyses revealed that those who reported to be single had significantly higher scores in depression and oral control, and significantly lower scores in self-esteem, compared to those who were in a relationship or married. The same significant associations were found regarding prelockdown relationship status.

Having contracted or not COVID-19 (or not being sure about it) had a significant impact on depression, anxiety, stress, dieting, and bulimia and food preoccupation. Post-hoc analyses revealed that participants that were not sure about whether they had contracted the virus or not had significantly higher levels of anxiety, stress, dieting and bulimia and food preoccupation in comparison to those who had not contracted COVID-19, and significantly higher levels of stress and depression than those who had indeed suffered COVID-19. Furthermore, those who reported that had not been infected with coronavirus scored significantly higher in stress compared to those who had suffered the virus. Having a loved one that had suffered the virus only had a significant effect on anxiety and oral control. Specifically, according to post-hoc analyses, those who reported that a significant other had contracted the virus showed significantly higher levels of anxiety and oral control than those who did not have a loved one who had been infected with the virus. Moreover, participants that were not sure about whether a loved one had suffered coronavirus scored significantly higher in the oral control scale in compari- 


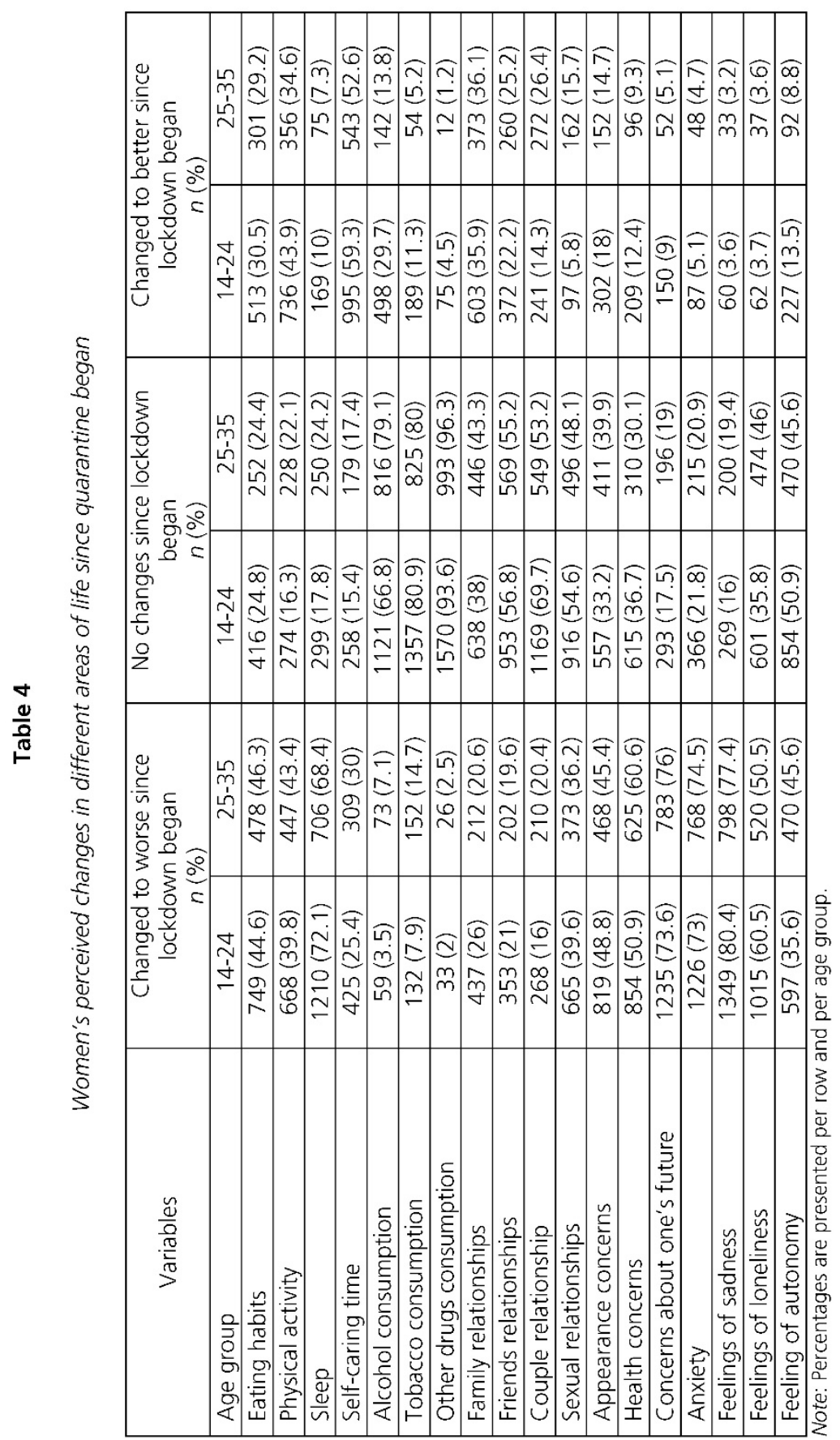




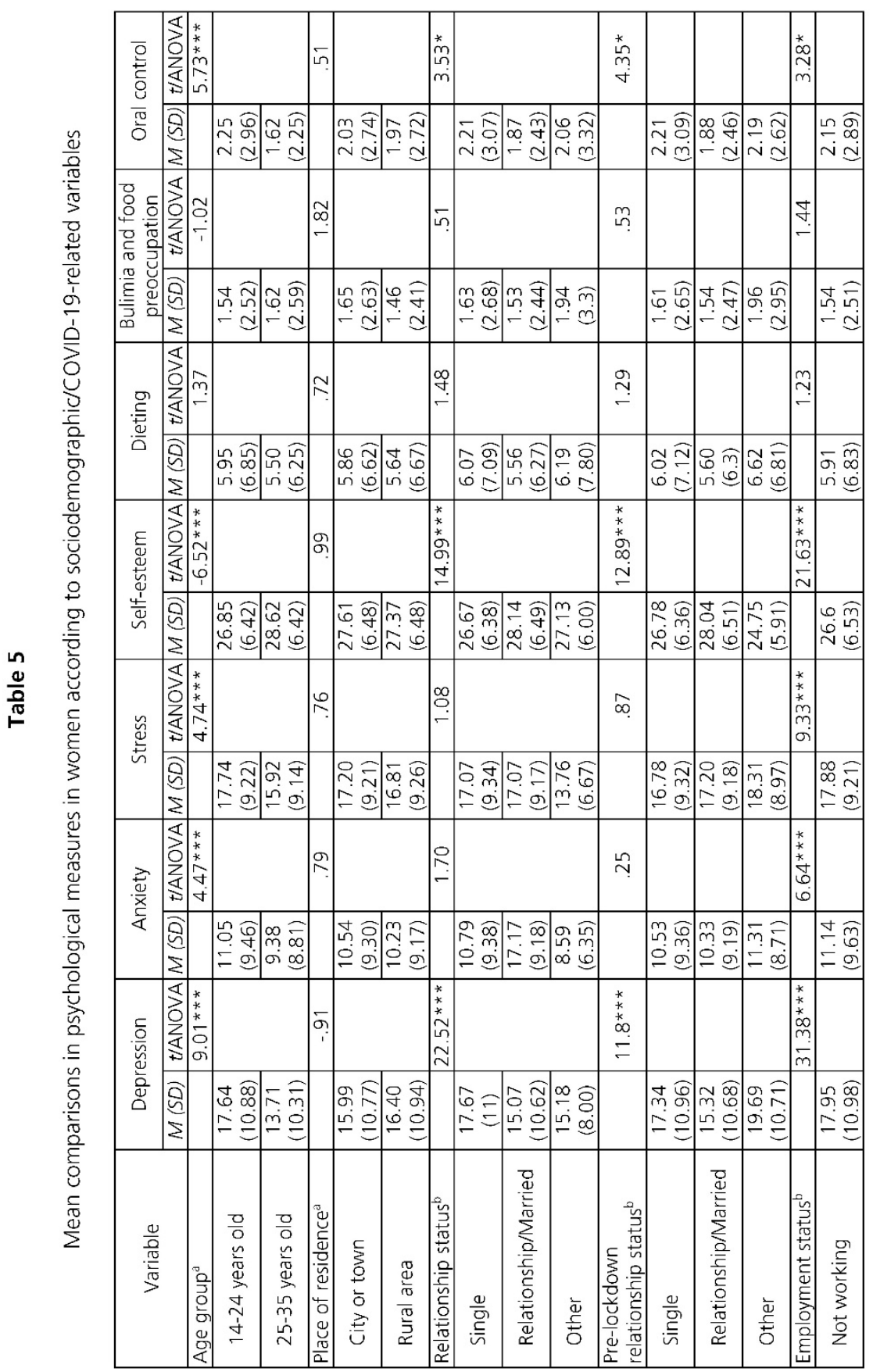




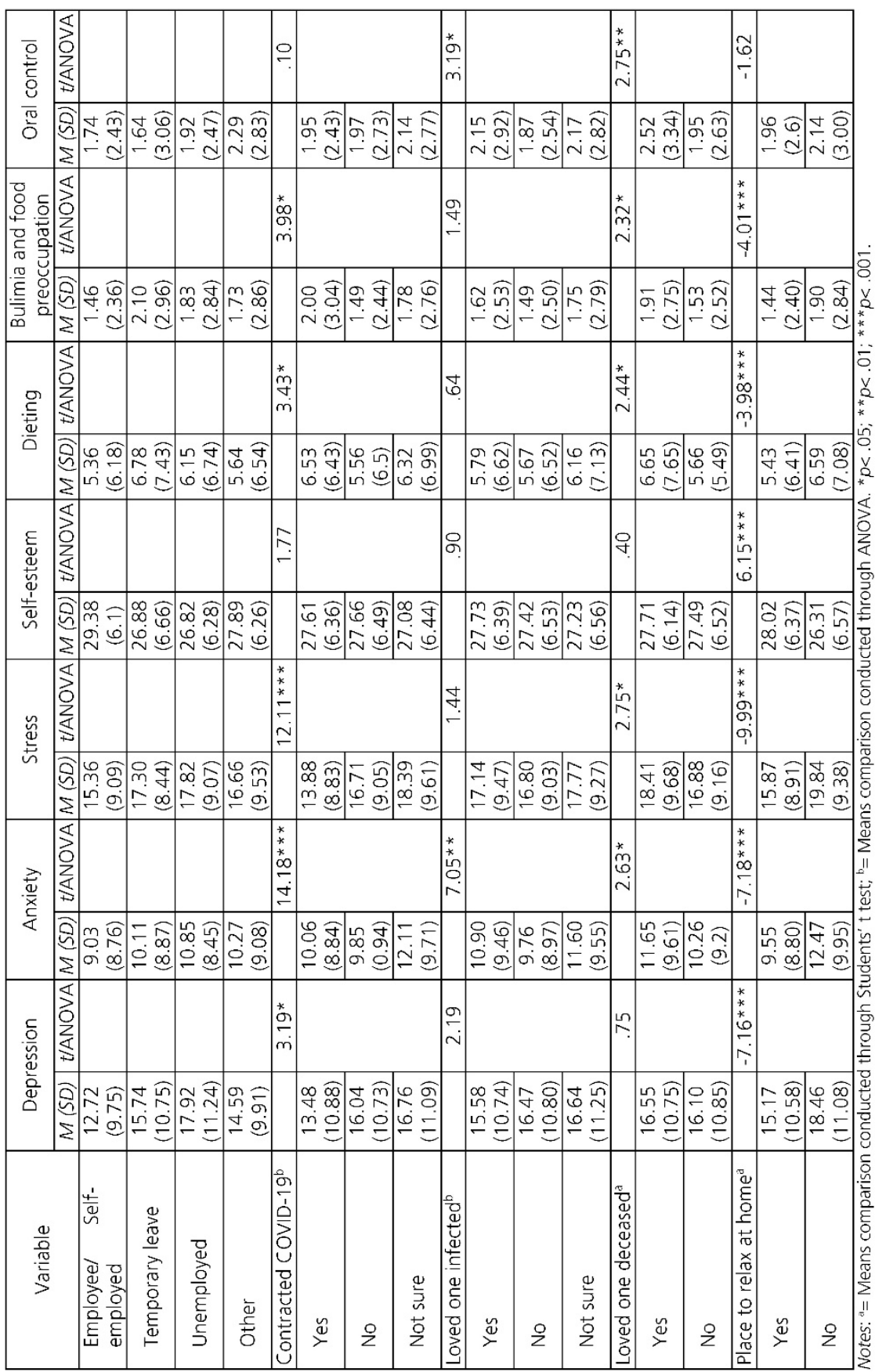


son to those who did not have a significant person that had contracted the virus. Significant differences were found in anxiety, stress, dieting, bulimia and food preoccupation, and oral control depending on whether participants had experienced the loss of a significant person due to COVID-19. Finally, participants that stated that did not have a place at home to relax exhibited significantly higher levels of depression, anxiety, stress, dieting, bulimia and food preoccupation, and significantly lower levels of self-esteem, compared to those who considered that did have that space.

Psychological impact of the lockdown on anxiety, depression, and disordered eating in women

Structural equation modelling was applied to test a model in which the psychological impact of the lockdown was related to disordered eating symptomatology, as well as anxiety and depression symptoms. The proposed model included three latent variables - psychological wellbeing, eating symptoms, and anxiety and depression symptoms - which were the result of several indicators (Figure 1). The latent variable named psychological wellbeing gathered those variables related to the lockdown and that had a direct impact on participants' wellbeing, such as self-care time, appearance concerns, health concerns, and feeling of autonomy. Self-esteem was also considered as an indicator of the psychological impact of the lockdown, being considered as a protective factor for the negative psychological impact of the lockdown. As it can be seen in Figure 1, these indicators had a positive weight into the psychological impact latent variable, since higher values in every one of these indicators were related to higher participant's wellbeing and therefore a lower impact of lockdown. It has to be noted that self-esteem had the highest regression weight into the psychological impact latent variable indicating its key role as a protective factor against the psychological impact of the lockdown. The proposed model states that the psychological impact of the lockdown has a direct effect on two other latent variables: anxiety and depression, and disordered eating symptoms, being regression weights -.959 , and -.665 , respectively. Therefore, a lower psychological wellbeing was directly related to higher symptomatology of anxiety, depression, and disordered eating. Regression weights of anxiety and depression indicators ranged from .790 and .852, and from .461 to .848 in the disordered symptoms latent variable. It has to be noted that dieting and bulimia and food preoccupation were the subscales that obtained the higher regression weights regarding disordered eating. This model showed a good fit to data $\left(\chi^{2}[41]=402416.999, \mathrm{GF}=.997, \mathrm{CFl}=.990, \mathrm{NFI}=.990, \mathrm{SRMR}=.055\right)$, indicating that the psychological impact of the lockdown had a direct effect on anxiety and depression, as well as in eating symptomatology. 

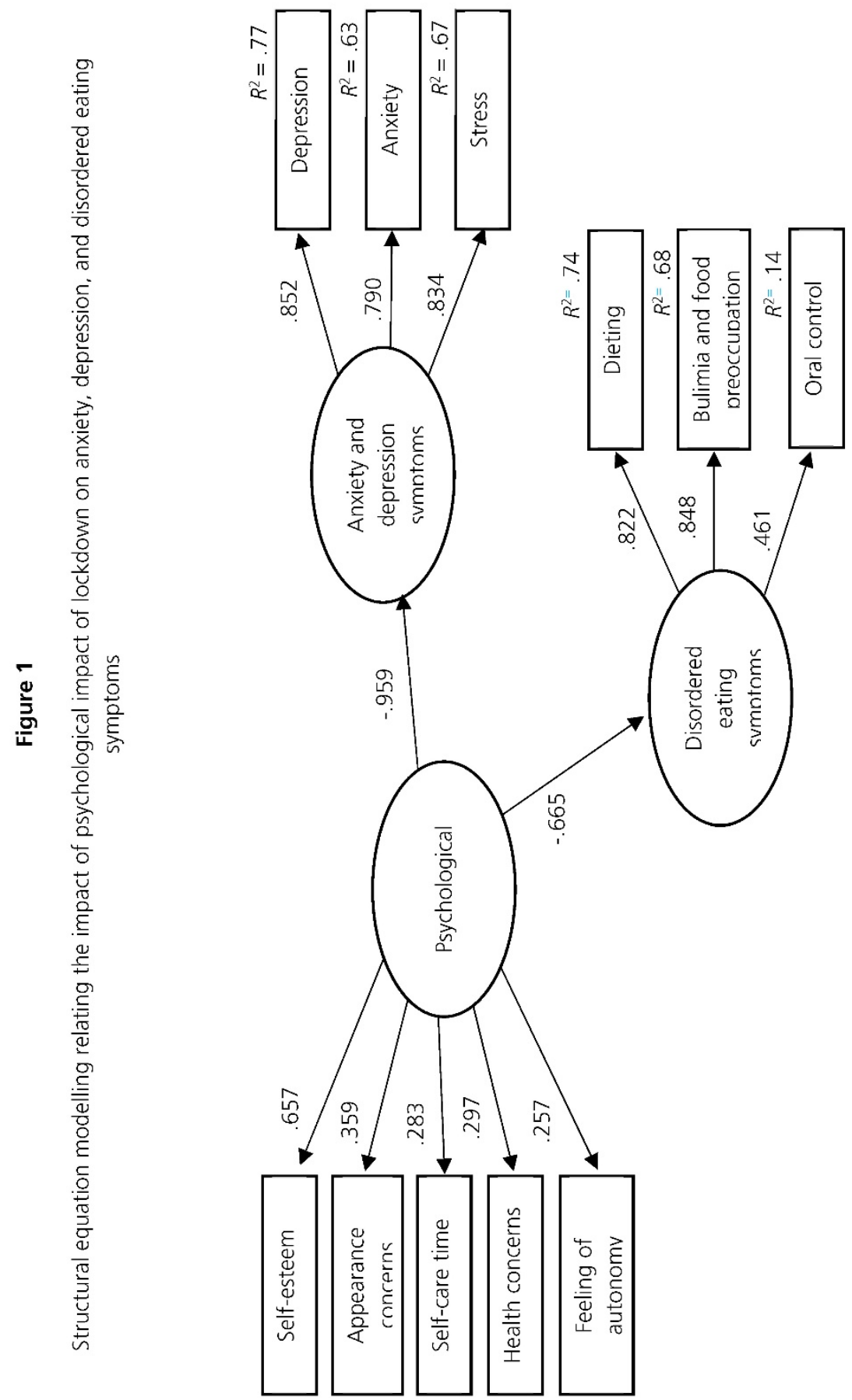


\section{Discussion}

The aim of this study was to explore the impact of COVID-19 and its associated lockdown on depression, anxiety, stress, self-esteem, and disordered eating in a community sample of Spanish adolescents and young people.

Significant differences were found in disordered eating between men and women, which aligns with previous literature (e.g., Elgin \& Pritchard, 2006, González et al., 2018), being women those who were at a higher risk for developing an eating disorder. Moreover, men and women also differed in several sociodemographic and COVID-19 related variables, including employment situation, their relationship status, and their feeling of having a place where they could relax at home.

It is well-known that the strict isolation measures in hospitals due to COVID-19 have had a significant psychological impact on both patients and their families. Accordingly, the present study found that the vast majority of people who had suffered the loss of a loved one due to coronavirus, had not had the chance of saying goodbye to them. This should be taken into consideration as it might result in complicated grief, and new rituals for honoring death in times of coronavirus could be implemented as a mitigating strategy.

Furthermore, the results of this research indicated that around one quarter of the sample were experiencing severe or extremely severe levels of depression, anxiety, and stress. These results are in line with the ones reported by OdriozolaGonzález et al. (2020), but they differ from the ones obtained by Wang et al. (2020) and Ozamiz-Etxebarria et al. (2020), who reported much lower levels of depression, anxiety, and stress in Chinese and Northern Spanish samples, respectively. This discrepancy could be explained by the fact that these two studies were conducted in the initial phases of the COVID-19 outbreak, when people were probably still not aware of the pandemic's scope, and lockdown measures were just being implemented, and therefore psychological distress was not as profound.

From our results, it seems clear that lockdown has had an impact on many life domains. The majority of women reported a deterioration in sleep quality, which goes in accordance with other recently published studies (Huang \& Zhao, 2020). Similarly, almost half of the women indicated that their eating habits and appearance concerns had worsened since lockdown began. Health concerns, preoccupation about one's own future, anxiety and feelings of sadness and loneliness had also worsened since the beginning of lockdown.

On the contrary, more than half of the sample reported that they were spending more time caring for themselves. As Spanish population was forced to stay at home most of the time when the data was collected, this possibly allowed people to have more time to do self-caring activities that they could not do before.

Surprisingly, a considerable proportion of women, especially the youngest ones, indicated that they were doing more physical activity at that time than before lockdown. This could be related to the fact that when participants completed the survey it was allowed to go out only to engage in individual sports activities, after several weeks of total confinement. Hence, it is possible that adolescents and young adults took advantage of that and started exercising more than they used to before 
the pandemic. It should also be noted that many other women indicated that they were exercising less at that time than before lockdown.

Moreover, confinement has had an impact on social relations on nearly half of the sample, in some cases improving family, friends and couple relationships, and in some other cases deteriorating them.

In accordance with other authors (e.g., Ozamiz-Etxebarria et al., 2020), the present study found that the youngest participants (generation Z) were more depressed and distressed than the older ones (generation $Y$ or Millennials). In alignment with this result, $62 \%$ of students felt that there had been an increase in assignments since lockdown began. Therefore, young students might have experienced additional stress due to the need to adapt to the new online educational environment. This should be taken into consideration and, as suggested by OzamizEtxebarria et al. (2020), teaching institutions might have to implement prevention and intervention programs to mitigate the emotional impact of the pandemic and its associated lockdown.

Unlike the findings reported by Cao et al. (2020), that indicated that living in urban areas was a protective factor against anxiety, the place of residence did not seem to have an impact on psychological distress in our sample. This difference might be partly due to cultural differences, as the imbalance of resources between urban and rural areas in Spain is much less pronounced than in China.

Participants that were unemployed were more depressed, anxious, and stressed, and had a lower self-esteem, than those who had a job. This finding goes in accordance with the well-documented fact that unemployment is associated with psychological distress and feelings of worthlessness (Farré, Fasani, \& Mueller, 2018), and is of paramount importance as unemployment has surged as a result of the coronavirus pandemic.

Surprisingly, women that were not sure about whether they had been infected with the virus or not were more depressed and stressed in comparison to participants who had suffered COVID-19. Similarly, women that had not been infected with coronavirus were more stressed than those who had indeed suffered the virus. One possible explanation for these findings is that people who have recovered from the virus might be less worried about the health-damaging consequences of COVID-19. Also, especially during the first weeks of the outbreak, Spain faced coronavirustesting shortages, therefore many people did not know whether they were infected or not, which could have led to an increase in emotional distress.

It was also found that women who had suffered the loss of a close person due to COVID-19 were more distressed and showed greater eating disturbances. This goes in accordance with the literature (Bennett, Greene, \& Schwartz-Barcott, 2013; Goldbacher et al., 2012; Loth, van den Berg, Eisenberg, \& Neumark-Sztainer, 2008), as stressful life events have been reported to be positively associated with disordered eating behaviors, and emotional eating has been defined as eating in response to emotional cues often as a way of coping with negative emotions. In this regard, grief may affect psychological wellbeing and lead to disturbed eating.

Moreover, emotional distress and eating disturbances were more prevalent in women who considered that did not have a place at home where they could relax. 
This should be taken into consideration as it might suggest a higher lockdown burden for lower income families.

A structural equation model including both COVID-19-related variables and psychological measures was tested in order to analyze the multivariate relationship between these variables. Results showed that the psychological impact of the lockdown in terms of variables that were related to participants' wellbeing had a direct effect on disordered eating and emotional distress (anxiety, depression, and stress). As expected, a higher psychological impact of the lockdown-related variables and lower self-esteem were directly related to higher levels of emotional distress and disordered eating in women. Therefore, this model confirms the direct influence of lockdown-related variables into psychopathology symptoms, in terms of disordered eating, and emotional distress.

The current study has several limitations that should be noted. First, part of the results included women only, as they constituted the majority of the sample. Therefore, further research should aim at examining the impact of lockdown on men. Second, even though this research reported the prevalence of participants who did not identify within the gender binary system as recommended by Cameron and Stinson (2019), these individuals were not included in the statistical analyses that were conducted separately for men and women due to their small sample size. Third, causality cannot be assumed among variables as the study had a cross-sectional design.

It should also be taken into consideration that when the study was conducted there was greater freedom of movement in Spain compared to the initial weeks of lockdown. Hence, data collection does not correspond with the contagious peak.

In conclusion, considering that COVID-19 has triggered the largest enforced isolation in living human history, early strategies are needed in order to tackle the adverse psychological effects derived from the pandemic and its associated confinement. Furthermore, it has been suggested that factors such as inadequate supplies and information, boredom, stigma and financial loss can have a negative psychological effect, and young people, individuals from disadvantaged backgrounds, and people with lower educational qualifications seem to be especially vulnerable (Brooks et al., 2020). Therefore, all these aspects should be carefully considered when designing plans and programs to help mitigate the psychological consequences.

\section{References}

Bados, A., Solanas, A., \& Andrés, R. (2005). Psychometric properties of the Spanish version of Depression, Anxiety and Stress Scales (DASS). Psicothema, 17(4), 679-683.

Bennett, J., Greene, G., \& Schwartz-Barcott, D. (2013). Perceptions of emotional eating behavior. A qualitative study of college students. Appetite, 60, 187-192. http://doi.org/10.1016/j.appet.2012.09.023

Bentler, P. M. (1990). Comparative fit indexes in structural models. Psychological Bulletin, 107(2), 238-246.

Bentler, P. M. (2005). EQS 6 Structural equations program manual. Encino, CA. Multivariate Software, Inc.

Bentler, P. M., \& Bonet, D. G. (1980). Significance tests and goodness of fit in the analysis of covariance structures. Psychological Bulletin, 88, 588-606. 
Brooks, S. K., Webster, R. K., Smith, L. E., Woodland, L., Wessely, S., Greenberg, N., \& Rubin, G. J. (2020). The psychological impact of quarantine and how to reduce it: Rapid review of the evidence. The Lancet, 395, 912-920. doi: 10.1016/S0140-6736(20)30460-8

Cameron, J. J., \& Stinson, D. A. (2019). Gender (mis)measurement: Guidelines for respecting gender diversity in psychological research. Social and Personality Psychology Compass, 13(11). doi: 10.1111/spc3.12506

Cao, W., Fang, Z., Hou, G., Han, M., Xu, X., Dong, J., \& Zheng, J. (2020). The psychological impact of the COVID-19 epidemic on college students in China. Psychiatry Research, 287, 1-5. doi: 10.1016/j.psychres.2020.112934

Castro, J., Toro, J., Salamero, M., \& Guimerá, E. (1991). The Eating Attitudes Test: Validation of the Spanish version. Evaluación Psicológica, 7(2), 175-189.

Duffy, B., Shrimpton, H., Clemence, M., Thomas, F., Whyte-Smith, H., \& Abboud, T. (2018). Beyond binary: The lives and choices of generation Z. London: Ipsos Mori.

Elgin, J., \& Pritchard, M. (2006). Gender differences in disordered eating and its correlates. Eating and Weight Disorders, 11(3), e1-e6. doi: 10.1007/BF03327565

Farré, L., Fasani, F., \& Mueller, H. (2018). Feeling useless: The effect of unemployment on mental health in the Great recession. IZA Journal of Labor Economics, 7(8), 1-34. doi: 10.1186/s40172-018-0068-5

Francis, T., \& Hoefel, F. (2018). 'True gen': Generation Z and its implications for companies. McKinsey\&Company. Retreived from https://www.mckinsey.com/industries/consumerpackaged-goods/our-insights/true-gen-generation-z-and-its-implications-forcompanies\#

Gale, L. (2015). Anxiety and depression assessment: Using the Depression Anxiety Stress Scales. Social Work Practice \& Skill, 1-5.

Garner, D. M., Olmsted, M. P., Bohr, Y., \& Garfinkel, P. E. (1982). The Eating Attitudes Test: Psychometric features and clinical correlates. Psychological Medicine, 12(4), 871-878. doi: $10.1017 / 50033291700049163$

Goldbacher, E. M., Grunwald, H. E., LaGrotte, C. A., Klotz, A. A., Oliver, T. L., Musliner, K. L., VanderVeur, S. S., \& Foster, G. D. (2012). Factor structure of the Emotional Eating Scale in overweight and obese adults seeking treatment. Appetite, 59, 610-615. doi: 10.1016/j.appet.2012.04.005

González, M. L., Penelo, E., Espinoza, P., Francisco, R., Mora, M., Gutiérrez, T., \& Raich, R. M. (2018). Insatisfacción corporal y actitudes alimentarias alteradas en adolescentes de Portugal y España [Body dissatisfaction and disordered eating attitudes among adolescents from Portugal and Spain]. Behavioral Psychology/Psicología Conductual, 26(2), 323-335.

Hou, T., Zhang, T., Cai, W., Song, X., Chen, A., Deng, G., \& Ni, C. (2020). Social support and mental health among health care workers during coronavirus disease 2019 outbreak: A moderated mediation model. Plos one, 15(5), e0233831. doi: 10.1371/journal.pone.0233831

Hu, L. T., \& Bentler, P. M. (1999). Cutoff criteria for fit indexes in covariance structure analysis: Conventional criteria versus new alternatives. Structural Equation Modeling, 6, 1-55.

Huang, Y., \& Zhao, N. (2020). Generalized anxiety disorder, depressive symptoms and sleep quality during COVID-19 outbreak in China: A web-based cross-sectional survey. Psychiatry Research, 288, 112954. doi: 10.1016/j.psychres.2020.112954

Isomaa, R., Väänänen, J. M., Fröjd, S., Kaltiala-Heino, R., \& Marttunen, M. (2013). How low is low? Low self-esteem as an indicator of internalizing psychopathology in adolescence. Health Education and Behavior, 40(4), 392-399. doi: 10.1177/1090198112445481

Jackson, D. L., Gillaspy, J. A., \& Purc-Stephenson, R. (2009). Reporting practices in confirmatory factor analysis: An overview and some recommendations. Psychological Methods, 14, 6-23. 
John Hopkins University \& Medicine. (2020, July 18). How is the outbreak growing? https://coronavirus.jhu.edu/data/cumulative-cases

Jöreskog, K. F., Sörbom, D. (1986). LISREL VI: Analysis of linear structural relationships by maximum likelihood, instrumental variables, and least square methods. Morresville, NC: Scientific Software Inc.

Liang, L., Ren, H., Cao, R., Hu, Y., Qin, Z., Li, C., \& Mei, S. (2020). The effect of COVID-19 on youth mental health. Psychiatric Quarterly, 91, 841-852. doi: 10.1007/s11126-02009744-3

Liu, N., Zhang, F., Wei, C., Jia, Y., Shang, Z., Sun, L., Wu, L., Sun, Z., Zhou, Y., Wang, Y., \& Liu, W. (2020). Prevalence and predictors of PTSS during COVID-19 outbreak in China hardest-hit areas: Gender differences matter. Psychiatry Research, 287, 112921. doi: 10.1016/j.psychres.2020.112921

Loth, K., van den Berg, P., Eisenberg, M. E., \& Neumark-Sztainer, D. (2008). Stressful life events and disordered eating behaviors: Findings from Project EAT. Adolescent Health Brief I, 43(5), 514-516. doi: 10.1016/j.jadohealth.2008.03.007

Lovibond, P. F., \& Lovibond, S. H. (1995). The structure of negative emotional states: Comparison of the Depression Anxiety Stress Scales (DASS) with the Beck Depression and Anxiety Inventories. Behaviour Research and Therapy, 33(3), 335-343. doi: 10.1016/0005-7967(94)00075-U

Martín-Albo, J., Núñez, J. L., Navarro, J. G., \& Grijalvo, F. (2007). The Rosenberg Self-Esteem Scale: Translation and validation in university students. The Spanish Journal of Psychology, 10(2), 458-467. doi: 10.1017/S1138741600006727

Odriozola-González, P., Planchuelo-Gómez, Á., Irurtia, M. J., \& de Luis-García, R. (2020). Psychological effects of the COVID-19 outbreak and lockdown among students and workers of a Spanish university. Psychiatry Research, 290, 113108. doi: 10.1016/j.psychres.2020.113108

Ozamiz-Etxebarria, N., Dosil-Santamaria, M., Picaza-Gorrochategui, M., \& IdoiagaMondragon, N. (2020). Stress, anxiety, and depression levels in the initial stage of the COVID-19 outbreak in a population sample in the northern Spain. Cadernos de Saude Publica, 36(4), 1678-4464. doi: 10.1590/0102-311X00054020

Plohl, N., \&Bojan, M. (2020). Modeling compliance with COVID-19 prevention guidelines: The critical role of trust in science. Psychology, Health \& Medicine, 1-12. doi: 10.1080/13548506.2020.1772988

Rajkumar, R. P. (2020). COVID-19 and mental health: A review of the existing literature. Asian Journal of Psychiatry, 52, 1-5. https://doi.org/10.1016/j.ajp.2020.102066

Rosenberg, M. (1965). Society and the adolescent self-image. Princeton, NJ: Princeton University Press.

Rukuni, T. F., \& Maziriri, E. T. (2020). Data on corona-virus readiness strategies influencing customer satisfaction and customer behavioural intentions in South African retail stores. Data in Brief, 31, 105818. doi: 10.1016/j.dib.2020.105818

Sun, L., Sun, Z., Wu, L., Zhu, Z., Zhang, F., Shang, Z., Jia, Y., Gu, J., Zhou, Y., Wang, Y., Liu, N., \& Liu, W. (2020). Prevalence and risk factors of acute posttraumatic stress symptoms during the COVID-19 outbreak in Wuhan, China. MedRxiv. doi: 10.1101/2020.03.06.20032425

Tang, W., Hu, T., Yang, L., \& Xu, J. (2020). The role of alexithymia in the mental health problems of home-quarantined university students during the COVID-19 pandemic in China. Personality and Individual Differences, 165, 110131. doi: 10.1016/j.paid.2020.110131

Wang, C., Pan, R., Wan, X., Tan, Y., Xu, L., Ho, C. S., \& Ho, R. C. (2020). Immediate psychological responses and associated factors during the initial stage of the 2019 coronavirus disease (COVID-19) epidemic among the general population in China. 
International Journal of Environmental Research and Public Health, 17(5), 1729. doi: 10.3390/ijerph17051729

Xiao, H., Zhang, Y., Kong, D. S., Li, S. Y., \& Yang, N. X. (2020). Social capital and sleep quality in individuals who self-isolated for 14 days during the coronavirus disease 2019 (COVID19) outbreak in January 2020 in China. Medical Science Monitor, 26, e923921. doi: 10.12659/MSM.923921

Zhu, H., \& Deng, F. (2020). How to influence rural tourism intention by risk knowledge during COVID-19 containment in China: Mediating role of risk perception and attitude. International Journal of Environmental Research and Public Health, 17, 10. doi: 10.3390/ijerph17103514

RECEIVED: July 18, 2020

ACCEPTED: November 2, 2020 